\title{
New-Generation Transcatheter Aortic Valves in Patients With Small Aortic Annuli \\ - Comparison of Balloon- and Self-Expandable Valves in Asian Patients -
}

\author{
Kazuaki Okuyama, MD; Masaki Izumo, MD; Tomoki Ochiai, MD; Shingo Kuwata, MD; \\ Toshiki Kaihara, MD; Masashi Koga, MD; Ryo Kamijima, MD; \\ Yuki Ishibashi, MD; Yasuhiro Tanabe, MD; Takumi Higuma, MD; \\ Raj Makkar, MD; Takeshi Miyairi, MD; Yoshihiro J Akashi, MD
}

\begin{abstract}
Background: Asian patients have smaller aortic annuli. Although 20-mm balloon-expandable (BE) transcatheter heart valves (THV) are manufactured for transcatheter aortic valve implantation (TAVI) in these cases, the supra-annular design of self-expandable (SE) THV is considered more suitable; however, real-world comparative data are scarce.

Methods and Results: Consecutive TAVI cases $(n=330)$ in a single Japanese center were reviewed. Based on the cutoff for the new-generation 20-/23-mm BE-THV, a small aortic annulus was defined as $<330 \mathrm{~mm}^{2}$. A considerable number of patients had small annuli: 49/302 (16\%). Of these, 33 BE-THV and 13 SE-THV using new-generation valves were compared. Although the SE-THV group had smaller annulus area (median 297 (interquartile range, 280-313) vs. 309 (303-323) mm² $(P=0.022)$ ), it had more favorable post-procedural parameters; for SE-THV and BE-THV, respectively, effective orifice area (EOA), $1.5(1.3-1.6) \mathrm{vs} .1 .1 \mathrm{~cm}^{2}(0.9-1.3)$ $(\mathrm{P}=0.002)$; mean pressure gradient, 7.6 (5.6-11.0) vs. $14.2 \mathrm{mmHg}(11.2-18.8)(\mathrm{P}=0.001)$; and peak velocity, 1.8 (1.6-2.4) vs. $2.7 \mathrm{~m} / \mathrm{s}$ (2.3-3.1) $(\mathrm{P}=0.001)$. Although new left bundle branch block was higher with SE-THV (24\% and $62 \%, P=0.02)$, patient-prosthesis mismatch $(\mathrm{PPM}) \geq$ moderate (indexed EOA $<0.85 \mathrm{~cm}^{2} / \mathrm{m}^{2}$ ) was significantly less with SE-THV than with BE-THV $(8 \%$ vs. $55 \%$; $\mathrm{P}=0.04)$. Hemodynamic findings were consistent up to 1 year.
\end{abstract}

Conclusions: Small annuli are often seen in Asian patients, for whom SE-THV implantation results in favorable hemodynamics with less PPM.

Key Words: Aortic annulus; Aortic valve replacement; Computed tomography; Complications; Valve prosthesis

$\mathbf{T}$ ranscatheter aortic valve implantation (TAVI) is increasingly used throughout the world, and in a variety of races, and its indication is shifting towards lower surgical risk. ${ }^{1-3}$ Although this catheter treatment is maturing and outcomes are improving, some controversies persist.

Prosthesis-patient mismatch (PPM) is one of the major concerns following TAVI. The term was invented in $1978,{ }^{4}$ and has been established as a mortality predictor after surgical aortic valve replacement (SAVR). ${ }^{\mathbf{5}, 6}$ TAVI results in a larger effective orifice area (EOA) compared with SAVR, ${ }^{7,8}$ and fewer cases of PPM are reported. The incidence rate of PPM following SAVR ranges from $20 \%$ to
$70 \%,{ }^{9}$ whereas moderate and severe PPM (moderate PPM: indexed EOA between 0.65 and $0.85 \mathrm{~cm}^{2} / \mathrm{m}^{2}$, and severe PPM: indexed EOA $<0.65 \mathrm{~cm}^{2} / \mathrm{m}^{2}$ ) after TAVI were reported by Miyasaka et al in $8.9 \%$ and $0.7 \%$, respectively, of cases, ${ }^{9}$ and in $25 \%$ and $12 \%$ by Herrmann et al. ${ }^{10}$ Although the incidence rates of PPM following TAVI are lower, a recent study of a large cohort reported that severe PPM was associated with higher rates of mortality and heart failure rehospitalization at 1 year. ${ }^{10}$ Furthermore, another study showed PPM was an independent predictor of structural valve deterioration, ${ }^{11}$ which may be a significant concern as the TAVI indication expands into lower risk and younger patients in whom the valves are expected

Received April 23, 2020; revised manuscript received July 2, 2020; accepted July 15, 2020; J-STAGE Advance Publication released online September 30, 2020 Time for primary review: 25 days

Division of Cardiology, Department of Internal Medicine (K.O., M.I., S.K., T.K., M.K., R.K., Y.I., Y.T., T.H., Y.J.A.), Cardiovascular Surgery (T.M.), St. Marianna University School of Medicine, Kawasaki, Japan; Heart Institute, Cedars-Sinai Medical Center, Los Angeles, CA (T.O., R.M.), USA

Mailing address: Kazuaki Okuyama, MD, Division of Cardiology, Department of Internal Medicine, St. Marianna University School of Medicine, 2-16-1 Sugao, Miyamae-ku, Kawasaki 216-8511, Japan. E-mail: kazu-823@hotmail.co.jp

All rights are reserved to the Japanese Circulation Society. For permissions, please e-mail: cj@j-circ.or.jp

ISSN-1346-9843 


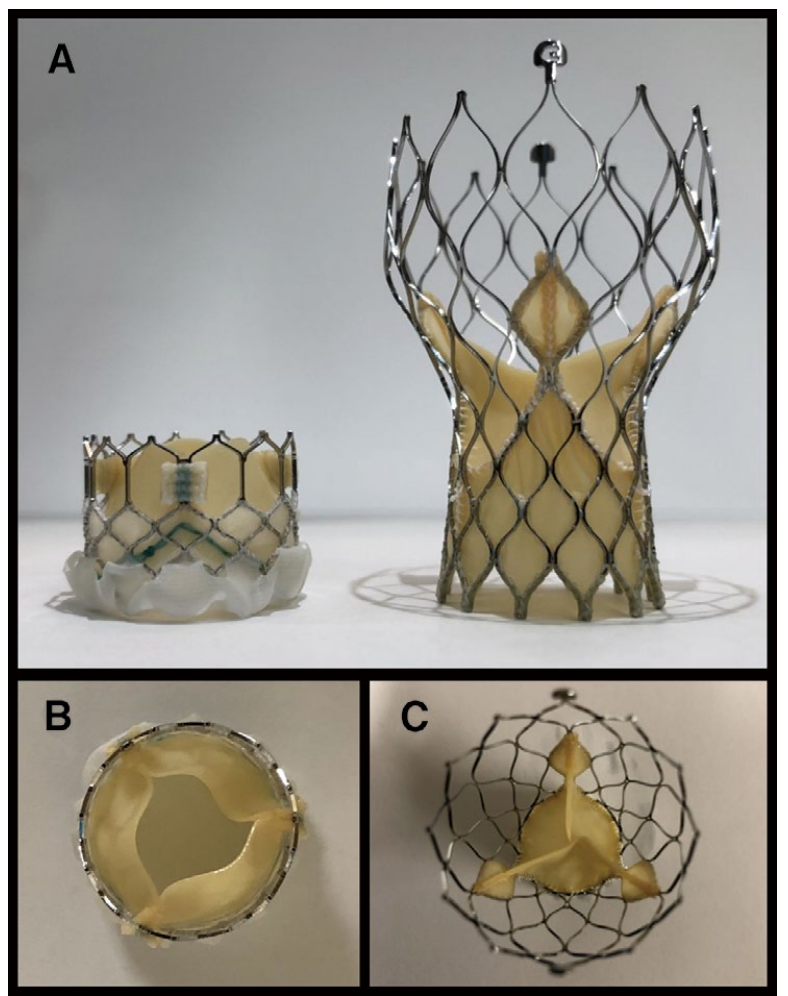

Figure 1. Design of the balloon- and self- expandable transcatheter valves. (A) Side view: (Left) balloon-expandable valve (20-mm Sapien 3), (Right) self-expandable valve (23$\mathrm{mm}$ Evolut R). Top view of the (B) balloon-expandable valve and (C) self-expandable valve. to function for a longer period.

TAVI emerged from Western countries, and now many procedures are being performed in Asian countries as well. Asian patients have much smaller aortic annuli than Caucasians. Watanabe et al. reported that annulus diameter was significantly smaller in a Japanese cohort than in a French cohort, ${ }^{12}$ and a small annulus is an independent predictor for PPM. ${ }^{9}$ A strategy for gaining larger EOA and avoiding PPM is important for patients with small annuli.

The hemodynamic outcomes of the balloon-expandable (BE) transcatheter heart valve (THV) are related to the native annular area, ${ }^{13}$ and the minimum size of the BETHV $(20 \mathrm{~mm})$ reveals a high mean gradient and a considerable risk for an increased rate of PPM. ${ }^{\mathbf{1 4}, 15}$ On the other hand, the supra-annular design (Figure 1) of the selfexpandable (SE) THV enables expansion of the EOA and is considered to be suitable for small annuli; however, there is little data comparing the hemodynamic outcomes between the SE-THV and BE-THV in patients with small annuli. This study sought to evaluate the acute hemodynamic and clinical outcomes between BE- and SE-THV in Asian patients with small annuli.

\section{Methods}

\section{Study Population and Design}

This study retrospectively reviewed 330 consecutive patients undergoing TAVI from January 2016 to March 2019 in a single center in Japan (Figure 2). Valve-in-valve TAVI and patients without annulus assessment by contrast computed tomography were excluded. The BE-THV devices were Sapien XT and Sapien 3 (Edwards Lifesciences, Irvine, CA, USA), and the SE-THV were Corevalve, Evolut R and Evolut Pro (Medtronic, Minneapolis, MN, USA). The selection of valve type and other procedural strategies were decided by a multidisciplinary heart team including cardiothoracic surgeons, anesthesiologists, interventional cardiologists and echocardiography cardiologists. During this

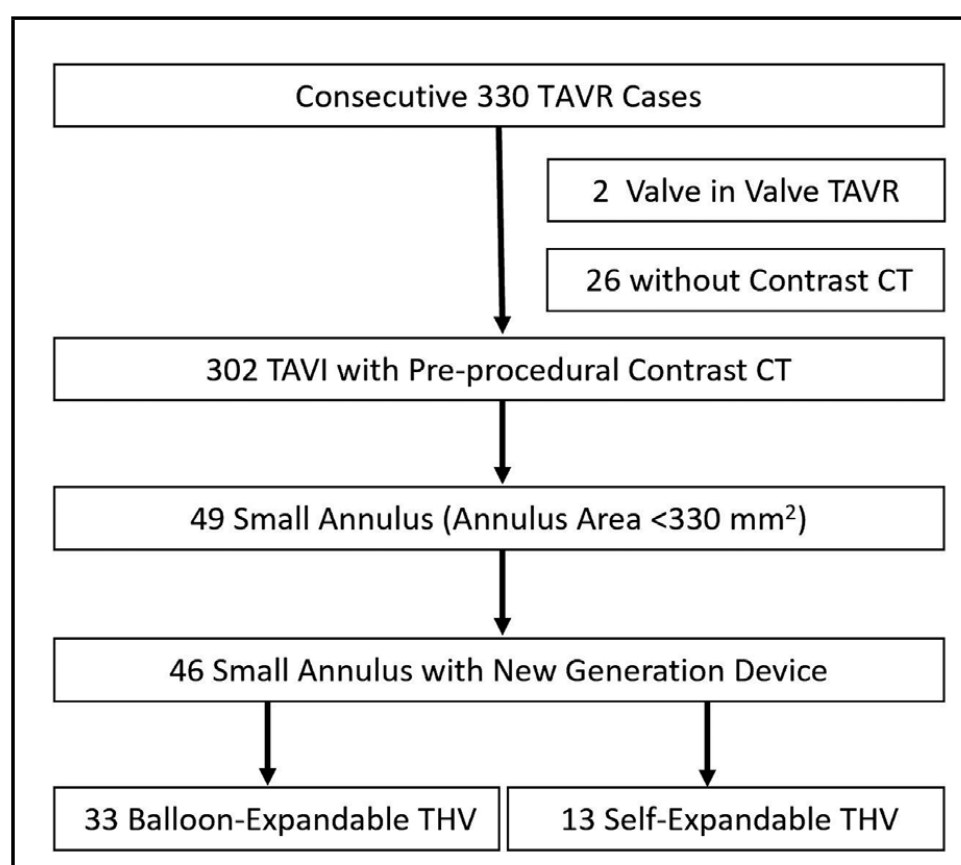

Figure 2. Flow chart of patient selection. TAVI, transcatheter aortic valve implantation; THV, transcatheter heart valve. 


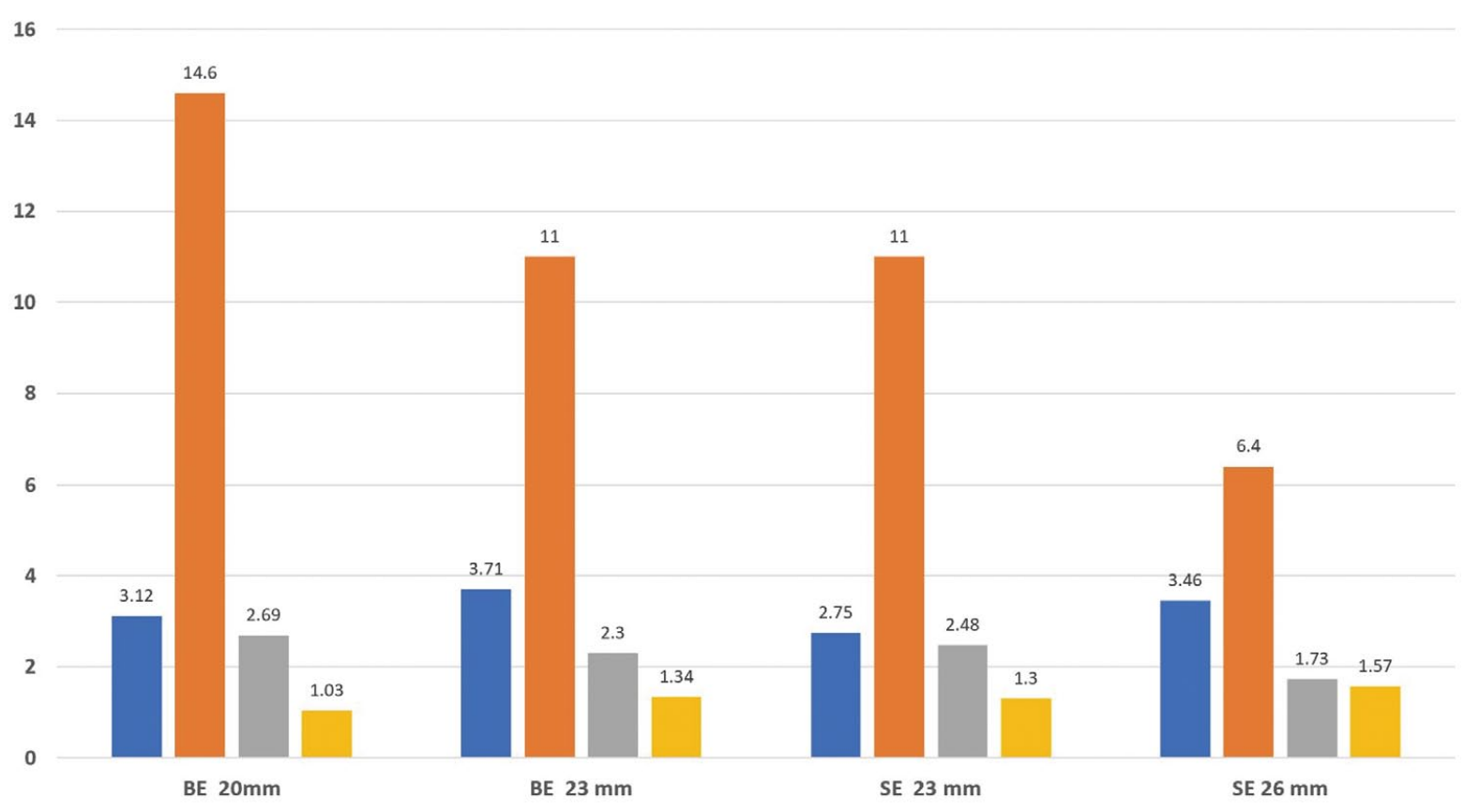

- Annulus Area $\left(\mathrm{cm}^{2}\right) \square$ Pressure Gradient $(\mathrm{mmHg}) \square$ Peak Velosity $(\mathrm{m} / \mathrm{s}) \square$ Effective Orifice Area $\left(\mathrm{cm}^{2}\right)$

Figure 3. Native annulus area and post-TAVI hemodynamics for each device. BE, balloon-expandable valve; SE, self-expandable valve.

study period, there were 8 TAVI operators who were involved in the heart team conference. The selection of BE- or SE-THV was multifactorial. Examples of factors that can influence device selection are: BE-THV preferred cases have low coronary height, small sinus of Valsalva, horizontal aorta and preoperative right bundle branch block, whereas SE-THV preferred cases have low pressure gradient aortic stenosis, high risk of annulus rupture due to severe calcification, high risk for rapid pacing (severe carotid artery stenosis or other severe valve disorder etc.) and small peripheral access. All procedures were performed under general anesthesia using transesophageal echocardiography assessment.

For our comparison of BE-THV and SE-THV, we selected patients with the newer generation devices (Sapien 3, Evolut R and Evolut Pro). A small annulus was defined as having an area $<330 \mathrm{~mm}^{2}$ based on the cutoff for the minimum size BE-THV (20-mm Sapien 3). ${ }^{15}$ Procedural, in-hospital, 30-day and 1-year outcomes were reviewed. Echocardiography was performed prior to the procedure, 1-2 days after the procedure and at the 30-day and 1-year follow-ups. Outcomes of newer generation BE-THV and SE-THV in small annuli were compared.

The study was conducted with approval from the institutional review board. All patients agreed to participate in the study and written informed consent was given by all patients. The investigation was performed according to the Declaration of Helsinki.

\section{Endpoint Definition}

Outcome data was reviewed up to 1-year follow-up. Endpoints were defined based on the Valve Academic Research Consortium-2 definition. ${ }^{16}$
PPM occurs in the setting of a morphologically normal valve and is considered to be hemodynamically insignificant if the indexed EOA is $>0.85 \mathrm{~cm}^{2} / \mathrm{m}^{2}$, moderate if between 0.65 and $0.85 \mathrm{~cm}^{2} / \mathrm{m}^{2}$, and severe if $<0.65 \mathrm{~cm}^{2} / \mathrm{m}^{2}$.

The composite endpoints are briefly described. Device success was defined as (1) absence of procedural death, (2) correct positioning of a single prosthetic heart valve into the proper anatomical location and (3) the intended performance of the prosthetic heart valve (no PPM and mean aortic valve gradient $<20 \mathrm{mmHg}$ or peak velocity $<3 \mathrm{~m} / \mathrm{s}$ and no moderate or severe prosthetic valve regurgitation). Endpoints for early safety were defined as (1) all-cause death, (2) all stroke (disabling and non-disabling), (3) lifethreatening bleeding, (4) acute kidney injury - stage 2 or 3 (including renal replacement therapy), (5) coronary artery obstruction requiring intervention, (6) major vascular complications, and (7) valve-related dysfunction requiring a repeat procedure. Clinical efficacy was defined as (1) allcause death, (2) all stroke (disabling and non-disabling), (3) requiring hospitalizations for valve-related symptoms or worsening congestive heart failure, (4) NYHA class III or IV, and (5) valve-related dysfunction (mean aortic valve gradient $\geq 20 \mathrm{mmHg}$, EOA $\leq 0.9-1.1 \mathrm{~cm}^{2}$ and/or a Doppler velocity index $<0.35 \mathrm{~m} / \mathrm{s}$, and/or moderate or severe prosthetic valve regurgitation).

\section{Statistical Analysis}

The data was collected retrospectively, and all the analyses were performed using the data from the as-treated population. Quantitative variables are expressed as median values (interquartile range), and qualitative variables are expressed as numbers with percentages. The Mann-Whitney U-test was used for quantitative variables, and Fisher's exact test 


\begin{tabular}{|c|c|c|c|}
\hline & $\begin{array}{c}\text { BE } \\
(n=33)\end{array}$ & $\begin{array}{c}\text { SE } \\
(n=13)\end{array}$ & $P$ value \\
\hline Age (years) & $84.0(79.5 \sim 88.5)$ & $84.0(82.5 \sim 87.0)$ & 0.72 \\
\hline Height (cm) & $146.0(140.5 \sim 149.5)$ & $140.0(137.0 \sim 149.5)$ & 0.19 \\
\hline Weight (kg) & $43.0(40.5 \sim 52.5)$ & $46.0(42.4 \sim 51.1)$ & 0.98 \\
\hline $\mathrm{BSA}\left(\mathrm{cm}^{2}\right)$ & $1.4(1.3 \sim 1.5)$ & $1.3(1.3 \sim 1.4)$ & 0.55 \\
\hline STS score & $4.8(3.5 \sim 8.2)$ & $5.6(3.6 \sim 5.9)$ & 0.96 \\
\hline Hemoglobin g/dL & $11.4(10.0 \sim 12.0)$ & $11.7(11.1 \sim 12.7)$ & 0.09 \\
\hline Creatinine (mg/dL) & $0.8(0.7 \sim 1.0)$ & $0.7(0.6 \sim 1.0)$ & 0.31 \\
\hline Bilirubin & $0.5(0.4 \sim 0.7)$ & $0.6(0.5 \sim 0.7)$ & 0.19 \\
\hline Annulus area $\left(\mathrm{mm}^{2}\right)$ & 309 (303 323) & 297 (280 313) & 0.022 \\
\hline $\mathrm{EF}(\%)$ & $69.0(62.5 \sim 73.5)$ & $67.0(65.0 \sim 71.0)$ & 0.46 \\
\hline MPG $(\mathrm{mmHg})$ & $43.8(30.7 \sim 61.4)$ & $29.4(23.4 \sim 48.6)$ & 0.12 \\
\hline Aortic valve area $\left(\mathrm{cm}^{2}\right)$ & $0.5(0.4 \sim 0.7)$ & $0.6(0.5 \sim 0.7)$ & 0.41 \\
\hline Aortic valve area index $\left(\mathrm{cm}^{2} / \mathrm{m}^{2}\right)$ & $0.4(0.3 \sim 0.5)$ & $0.4(0.4 \sim 0.5)$ & 0.22 \\
\hline Female & $32(97)$ & $13(100)$ & 0.72 \\
\hline Smoker & $1(3)$ & 0 & 0.72 \\
\hline Diabetes mellitus & $7(21)$ & $4(31)$ & 0.37 \\
\hline Dyslipidemia & $14(42)$ & $9(69)$ & 0.1 \\
\hline Hypertension & $27(82)$ & $12(92)$ & 0.35 \\
\hline Lung disease & $2(6)$ & 0 & 0.51 \\
\hline Peripheral artery disease & $5(15)$ & $1(8)$ & 0.45 \\
\hline Cerebral vascular disease & $4(12)$ & $2(15)$ & 0.55 \\
\hline Cardiovascular surgery & 0 & $1(8)$ & 0.28 \\
\hline Pacemaker implantation & $2(6.1)$ & 0 & 0.51 \\
\hline Coronary artery disease & $3(9)$ & $1(8)$ & 0.69 \\
\hline Atrial fibrillation & $4(12)$ & $1(8)$ & 0.56 \\
\hline Pulmonary hypertension & $6(18)$ & $2(15)$ & 0.6 \\
\hline $\mathrm{MR} \geq$ moderate & $2(6)$ & 0 & 0.51 \\
\hline Right bundle branch block & $7(21)$ & 0 & 0.08 \\
\hline Low coronary height $(\leq 10 \mathrm{~mm})$ & $6(18)$ & $1(8)$ & 0.35 \\
\hline Subannular calcification & $9(27)$ & $3(23)$ & 0.54 \\
\hline Less calcified leaflet & $7(21)$ & $1(8)$ & 0.27 \\
\hline
\end{tabular}

$\mathrm{BE}$, balloon-expandable valve; BSA, body surface area; EF, ejection fraction; MPG, mean pressure gradient; MR, mitral regurgitation; $\mathrm{SE}$, self-expandable valve.

was used for qualitative variables.

A $P$ value $\leq 0.05$ was considered statistically significant. The data were analyzed with SPSS software (PASW v18, SPSS, Inc.)

\section{Results}

\section{Patient Population}

Of the 330 consecutive cases of TAVI, there were 302 in which preprocedural contrast CT assessments had been performed. There was a considerable number of patients with a small annulus $(49(16 \%))$ and of them, a new-generation THV was used in 46 cases: 33 BE-THV and 13 SETHV (Figure 2).

\section{Differences in Hemodynamics Between Devices}

Native annulus area and the post-TAVI hemodynamics of each device were reviewed (Figure 3). Smaller THV were implanted in smaller annuli, and smaller THV revealed inconvenient parameters for both BE- and SE-THV. Although annulus area was the smallest in the 23-mm SETHV group (275 (264-291) $\left.\mathrm{mm}^{2}\right)$, the worst hemodynamics was in the 20-mm BE-THV group: pressure gradient, 14.6
(11.8-21.3) mmHg; peak velocity, $2.69(2.4-3.2) \mathrm{m} / \mathrm{s}$; EOA, $1.03(0.9-1.2) \mathrm{cm}^{2}$.

\section{Comparison of BE-THV and SE-THV}

BE-THV and SE-THV were compared in patients with a small annulus. Table 1 shows a comparison of the baseline characteristics of the 2 groups. At the baseline, there were no significant differences in age, height, weight, or body surface area, except that annulus area was significantly smaller in the SE-THV group compared with the BE-THV group: $297(280-313) \mathrm{mm}^{2}$ vs. $309(303-323) \mathrm{mm}^{2}(\mathrm{P}=0.022)$ (Table 1).

Procedural and in-hospital outcomes are shown in Table 2. We used the 20-mm and 23-mm BE-THV in 19 and 14 patients, respectively, and the $23-\mathrm{mm}$ and $26-\mathrm{mm}$ SE-THV in 5 and 8 patients, respectively. There was no case of a $20-\mathrm{mm}$ BE-THV being implanted using an underfilled balloon, but there were 2 cases of using an overfilled balloon with $0.5-1 \mathrm{~mL}$. On the other hand, most cases of 23 -mm BE-THV (12 cases) were implanted using an underfilled balloon with $1-2 \mathrm{~mL}$. The rates of post-implant dilatation and greater than mild paravalvular leak were not significantly different between groups ( $9 \%$ vs. $8 \%$, and $3 \%$ 


\begin{tabular}{|c|c|c|c|}
\hline & $\begin{array}{c}\text { BE } \\
(n=33)\end{array}$ & $\begin{array}{c}\text { SE } \\
(n=13)\end{array}$ & $P$ value \\
\hline \multicolumn{4}{|l|}{ Valve size } \\
\hline BE20 & 19 & - & - \\
\hline BE23 & 14 & - & - \\
\hline SE23 & - & 5 & - \\
\hline SE26 & - & 8 & - \\
\hline Underfilled balloon & $12(36)$ & NA & \\
\hline Post-implant dilatation & $3(9)$ & $1(8)$ & 0.69 \\
\hline Percutaneous closure device failure & 0 & $2(15)$ & 0.08 \\
\hline Procedural death & 0 & 0 & - \\
\hline Correct positioning of a single valve & $32(97)$ & $13(100)$ & 0.72 \\
\hline Procedure time $(\mathrm{min})$ & $80.0(58.5 \sim 111.5)$ & $77.0(65.5 \sim 102.0)$ & 0.79 \\
\hline New pacemaker implantation & $5(15)$ & $3(23)$ & 0.4 \\
\hline New left bundle branch block & $8(24)$ & $8(62)$ & 0.021 \\
\hline Lowest hemoglobin & $10.8(9.9 \sim 11.8)$ & $10.2(9.4 \sim 11.3)$ & 0.21 \\
\hline Highest creatinine & $0.8(0.6 \sim 1.0)$ & $0.7(0.6 \sim 0.9)$ & 0.49 \\
\hline Hospital stay (days) & $9.0(9.0 \sim 18.5)$ & $11.0(9.0 \sim 17.5)$ & 0.65 \\
\hline Paravalvular leak $\geq$ moderate & $1(3)$ & $1(8)$ & 0.49 \\
\hline EOA & $1.1(0.9 \sim 1.3)$ & $1.5(1.3 \sim 1.6)$ & 0.002 \\
\hline EOAI & $0.8(0.7 \sim 1.0)$ & $1.0(1.0 \sim 1.3)$ & 0.002 \\
\hline MPG $(\mathrm{mmHg})$ & $14.2(11.2 \sim 18.8)$ & $7.6(5.6 \sim 11.0)$ & 0.001 \\
\hline Peak velocity $(\mathrm{m} / \mathrm{s})$ & $2.7(2.3 \sim 3.1)$ & $1.8(1.6 \sim 2.4)$ & 0.001 \\
\hline $\mathrm{PPM} \geq$ moderate & $18(55)$ & $1(8)$ & 0.04 \\
\hline Severe PPM & $6(18)$ & 0 & 0.12 \\
\hline Device success & $14(42)$ & $13(100)$ & $<0.001$ \\
\hline
\end{tabular}

PPM $\geq$ moderate is indexed EOA $<0.85 \mathrm{~cm}^{2} / \mathrm{m}^{2}$; severe PPM is indexed EOA $<0.65 \mathrm{~cm}^{2} / \mathrm{m}^{2}$. EOA, effective orifice area; EOAI, effective orifice area index; PPM, patient-prosthesis mismatch. Other abbreviations as in Table 1.

vs. $8 \%$, for BE-THV and SE-THV, respectively). Although the difference was not significant, SE-THV showed numerically higher new pacemaker implantation ( $23 \%$ vs. $15 \%$; $\mathrm{P}=0.4)$. The rate of new left bundle branch block was significantly higher in the SE-THV group ( $62 \%$ vs. $24 \%$; $\mathrm{P}=0.021)$. Regarding the hemodynamic parameters for the prosthetic valves, the SE-THV group showed more favorable outcomes: EOA $1.1(0.9-1.3) \mathrm{cm}^{2}$ vs. $1.5(1.3-1.6) \mathrm{cm}^{2}$ $(\mathrm{P}=0.002)$; mean pressure gradient $14.2(11.2-18.8)$ vs. 7.6 (5.6-11.0) $\mathrm{mmHg}(\mathrm{P}=0.001)$; peak velocity 2.7 (2.3-3.1) $\mathrm{m} / \mathrm{s}$ vs. $1.8(1.6-2.4) \mathrm{m} / \mathrm{s}(\mathrm{P}=0.001)$, for BE and SE-THV, respectively. This led to significantly lower rates of PPM and higher rates of device success: PPM, 18 (55) vs. 1 (8) $(\mathrm{P}=0.04)$ and device success, $14(42)$ vs. $13(100)(\mathrm{P}<0.001)$, for BE- and SE-THV, respectively (Table 2).

\section{0-Day and 1-Year Follow-up}

As for the 30-day outcomes (Table 3), there were no deaths or strokes in either group. Although the BE-THV group had a few cases of life-threatening bleeding (bleeding at access site, gastrointestinal hemorrhage and alveolar hemorrhage) and stage 2 or 3 acute kidney injury, there was no significant difference in the early safety between the BEand SE-THV groups: 29 (91) vs. $12(100)(\mathrm{P}=0.7)$, respectively. Changes in ejection fraction and left ventricular diastolic diameter from baseline were measured by echocardiography, and there were no significant differences in these parameters of systolic function and cardiac size: $1.5 \%$ $(-2.0-5.8)$ vs. $4 \%(2-8)(\mathrm{P}=0.16)$ and $1.5 \mathrm{~mm}(-2.0-5.8)$ vs. $1 \mathrm{~mm}(-3-4)$, for BE- and SE-THV, respectively. The SE-
THV group had better hemodynamic parameters for EOA, EOAI, mean pressure gradient and peak velocity, as reflected in the in-hospital outcomes. The rate of PPM $\geq$ moderate was significantly higher in the BE-THV than the SE-THV group: 19 (59) vs. 2 (18) $(\mathrm{P}=0.018)$. Moreover, the 30-day follow-up revealed significantly higher incidence of severe PPM as well in the BE-THV group compared with the SE-THV group: 9 (28) vs. $0(\mathrm{P}=0.05)$. The 1 -year follow-up found 1 patient in the SE-THV group had died due to intestinal obstruction; however, the difference in mortality was not significant (Table 4). Other findings were consistent with the 30-day follow-up.

\section{Discussion}

For treatment of aortic stenosis, various options are becoming available and there are strategies for the prevention and management of PPM in patients with small annuli. Regarding SAVR, most of the valves have stents and sewing rings that reduce the EOA, but the design of the prosthesis can improve this inconvenience. Externally mounted pericardium (Mitroflow (Sorin Group), Trifecta (Abott Vascular)) can maximize transvalvular flow. ${ }^{17}$ In addition, the surgical technique can enable implantation of a larger valve. Supra-annular implantation has been associated with hemodynamic improvement over conventional intraannular positioning of the prosthesis. ${ }^{18}$ Aortic root enlargement, such as the Nicks technique, is an effective option for small annulus. Patients undergoing aortic enlargement reportedly have a lower incidence of PPM $\geq$ moderate: 


\begin{tabular}{|c|c|c|c|}
\hline & $\begin{array}{c}\text { BE } \\
(n=32)\end{array}$ & $\begin{array}{c}S E \\
(n=12)\end{array}$ & $P$ value \\
\hline All-cause death & 0 & 0 & - \\
\hline Stroke & 0 & 0 & - \\
\hline Life-threatening bleeding & $3(9)$ & 0 & 0.38 \\
\hline Acute kidney injury stage 2 or 3 & $2(6)$ & 0 & 0.52 \\
\hline Requiring hospitalization & $2(6)$ & 0 & 0.52 \\
\hline Early safety & $29(91)$ & $12(100)$ & 0.7 \\
\hline NYHA class III or IV & 0 & 0 & - \\
\hline Clinical efficacy & $19(59)$ & $12(100)$ & 0.07 \\
\hline Echocardiography findings & $(n=32)$ & $(n=11)$ & \\
\hline EOA & $1.1(0.9 \sim 1.3)$ & $1.4(1.1 \sim 1.6)$ & 0.07 \\
\hline EOAI & $0.8(0.6 \sim 1.0)$ & $1.0(0.9 \sim 1.4)$ & 0.09 \\
\hline MPG & $15.0(12.9 \sim 21.6)$ & $9.3(6.2 \sim 12.0)$ & $<0.001$ \\
\hline Peak velocity & $2.7(2.4 \sim 3.2)$ & $2.1(1.7 \sim 2.4)$ & $<0.001$ \\
\hline Change in EF (\%) & $1.5(-2.0 \sim 5.8)$ & $4(2 \sim 8)$ & 0.16 \\
\hline Change in LVDd (mm) & $1.5(-2.0 \sim 5.8)$ & $1(-3 \sim 4)$ & 0.63 \\
\hline $\mathrm{PPM} \geq$ moderate & $19(59)$ & $2(18)$ & 0.018 \\
\hline Severe PPM & $9(28)$ & 0 & 0.05 \\
\hline Paravalvular leak $\geq$ moderate & $1(3)$ & 0 & 0.74 \\
\hline Valve-related dysfunction & $13(41)$ & 0 & 0.009 \\
\hline
\end{tabular}

$\mathrm{PPM} \geq$ moderate is indexed EOA $<0.85 \mathrm{~cm}^{2} / \mathrm{m}^{2}$; severe PPM is indexed EOA $<0.65 \mathrm{~cm}^{2} / \mathrm{m}^{2}$. NYHA, New York Heart Association. Other abbreviations as in Tables 1,2.

\begin{tabular}{|c|c|c|c|}
\hline & $\begin{array}{c}\text { BE } \\
(n=31)\end{array}$ & $\underset{\substack{S \\
(n=12)}}{S E}$ & $P$ value \\
\hline All-cause death & 0 & $1(8.3)$ & 0.28 \\
\hline Heart failure hospitalization & 0 & 0 & - \\
\hline NYHA Class III or IV & 0 & 0 & - \\
\hline Echocardiography findings & $(n=28)$ & $(n=11)$ & \\
\hline EOA & $1.0(0.8 \sim 1.3)$ & $1.2(1.2 \sim 1.4)$ & 0.08 \\
\hline EOAI & $0.7(0.6 \sim 1.0)$ & $0.9(0.9 \sim 1.0)$ & 0.046 \\
\hline MPG & $17.4(12.0 \sim 20.1)$ & $8.2(4.2 \sim 10.3)$ & $<0.001$ \\
\hline Peak velocity & $2.8(2.4 \sim 3.1)$ & $1.8(1.5 \sim 2.4)$ & $<0.001$ \\
\hline Change in EF (\%) & $1.0(-3.8 \sim 6.5)$ & $1.0(-1 \sim 9)$ & 0.42 \\
\hline Change in LVDd (mm) & $0.5(-3.3 \sim 4.0)$ & $0(-2 \sim 3)$ & 0.83 \\
\hline $\mathrm{PPM} \geq$ moderate & $18(64)$ & $1(9)$ & 0.02 \\
\hline Severe PPM & $10(36)$ & 0 & 0.021 \\
\hline Paravalvular leak $\geq$ moderate & $4(14)$ & 0 & 0.25 \\
\hline
\end{tabular}

$\mathrm{PPM} \geq$ moderate is indexed EOA $<0.85 \mathrm{~cm}^{2} / \mathrm{m}^{2}$; severe PPM is indexed $\mathrm{EOA}<0.65 \mathrm{~cm}^{2} / \mathrm{m}^{2}$. Abbreviations as in Tables 1-3.

$42.6 \%$ vs. $69.4 \%$ in patients with and without this technique, respectively $(\mathrm{P}<0.001) .{ }^{19}$ These strategies enable an increased EOA following SAVR, but the durability of an externally mounted valve is still a concern; some studies revealed accelerated structural valve deterioration and increased reoperation rates with externally mounted valves. ${ }^{20-22}$ Moreover, the aortic root enlargement procedure includes incision of the annulus and patch reconstruction of the root, thus it is more complicated than simple SAVR. There is also expected to be greater chance of bleeding, and longer cardiac-arrest time. The prosthetic valve used in TAVI does not require a sewing ring and thus results in a larger EOA as compared with the surgical valves. Clavel et al revealed lower trans-prosthetic gradi- ents, higher indexed EOA, and reduced PPM rates with TAVI compared with SAVR. ${ }^{23}$ Therefore, TAVI is a potential strategy for small annuli.

TAVI emerged from Western countries, and now many procedures are being performed in Asian countries as well. Asian patients have smaller body size, and the 20-mm BETHV was specially manufactured for their small annuli; however, comparative data for SE-THV in small annuli are limited. The hemodynamic assessment in the current study showed that less favorable hemodynamics occurred with smaller sized devices, which is consistent with a previous study. ${ }^{13}$ In particular, the $20-\mathrm{mm}$ BE-THV revealed high residual pressure and velocity with a small EOA of $1.03 \mathrm{~cm}^{2}$ (Figure 3). SE-THV implantation showed signifi- 
cantly larger EOA resulting in lower rate of post-procedural PPM compared with BE-THV implantation. It is mainly owing to the supra-annular design of the SE-THV (Figure 1). Even if the native annulus is small, a higher prosthetic annulus enables to acquire extra EOA. This larger EOA is the advantage of the SE-THV, especially in patients with a small annulus. On the other hand, the SE-THV generally shows a higher chance of conduction disturbance. In our study as well, the SE-THV group showed higher rates of new pacemaker implantation and left bundle block. The design of the SE-THV requires deeper deployment and larger expansion in the left ventricular tract, which can cause this disadvantage. In contrast, the shorter metal of BE-THV allows easier access to the coronary artery and less chance of conduction disturbance; however, the prosthetic annulus must be accommodated at the native annulus level and does not create a larger EOA. The difference in the design of the SE- and BE-THV contributes to these strengths and weaknesses of each device.

A large registry of the Society of Thoracic Surgeons/ American College of Cardiology TVT (Transcatheter Valve Therapy) registry reported that severe PPM was associated with higher mortality and heart failure rehospitalization at 1 year; mortality was $17.2 \%, 15.6 \%$, and $15.9 \%$ in severe, moderate, and no PPM patients, respectively $(\mathrm{P}=0.02)$, and heart failure rehospitalization respectively occurred in $14.7 \%, 12.8 \%$ and $11.9 \%$ of patients $(\mathrm{P}<0.001) .{ }^{10}$ Our study did not show worse mortality with severe PPM, potentially because of the small number of study subjects. Une et al reported that PPM is an independent predictor of redo aortic valve replacement due to structural valve deterioration (odds ratio: $1.63 ; 95 \%$ confidence interval 1.01-2.63; $\mathrm{P}=0.045) .{ }^{11}$ As there is a widespread trend of younger patients undergoing TAVI, avoiding PPM is a major concern.

Hahn et al reported that the SAPIEN 3 post-implant EOA was progressively larger for each quintile of annular area $(\mathrm{P}<0.001)$, and similarly for the Evolut $\mathrm{R}$ valve, postimplantation EOA was significantly larger for each quintile of annular perimeter $(\mathrm{P}<0.001){ }^{13}$ This is consistent with our findings for the post-TAVI hemodynamics with each device, whereby smaller valves had less favorable parameters (Figure 3). Rogers et al reported that the SETHV in a small aortic annulus was associated with significantly higher dimensionless indexes $(0.64$ vs. $0.53, \mathrm{P}=0.02)$ and lower peak velocities $(1.8$ vs. $2.4 \mathrm{~m} / \mathrm{s}, \mathrm{P}<0.001)$ and a trend towards lower mean gradients $(7.5$ vs. $10.0 \mathrm{mmHg}$, $\mathrm{P}=0.07)$ compared with BE-THV. These differences were attenuated and absent in patients with medium to large annuli. ${ }^{24}$ In other words, the difference is vitally important in cohorts with small annuli, such as Asian populations.

The report by Rogers et al showed no significant difference in the PPM rate between BE-THV and SE-THV in patients with small annuli; moderate PPM was $8(42 \%)$ vs. $4(24 \%)(\mathrm{P}=0.17)$ and none of the patients had severe PPM. ${ }^{24}$ Our study showed significantly higher rates of PPM for BE-THV implantation, potentially because of the different definition of a small annulus. In our study, a small annulus was defined as an annulus area $<330 \mathrm{~mm}^{2}$ based on the cutoff for the minimum BE-THV (20-mm Sapien 3). The previous report divided the patients into textile groups based on perimeter, resulting in perimeter cutoffs of 73 and $80 \mathrm{~mm}$. A small annulus was defined as a perimeter $<73 \mathrm{~mm}$. As shown in our study, the $20-\mathrm{mm}$ BE-THV had inconvenient hemodynamic parameters post-TAVI. Moreover, all patients with severe PPM were implanted with the 20-mm BE-THV, except for 1 patient with a 23-mm BETHV. The cutoff in our study, which was based on the 20-mm BE-THV, may be reasonable for the purpose of avoiding PPM.

\section{Study Limitations}

This was a single-center study using retrospectively reviewed data and no randomization between the different devices was performed. Device selection is multifactorial, including anatomical factors, and the decision was at the discretion of the heart team. The selection bias is the major limitation of this study. As to the baseline characteristics, the SE-THV group showed smaller annulus areas. SETHV tended to be selected for patients with small annuli, which could be the reason for this difference. Although the SE-THV group had smaller annuli they showed more favorable hemodynamics after TAVI, and the conclusions of this study are consistent. Although multiple devices are available worldwide, the devices used for the study were limited (Sapien 3, Evolut R and Evolut Pro).

Further analysis in a larger multicenter, long-term study is warranted to definitively assess this question.

\section{Conclusions}

To our knowledge, this is the first study to show that the SE-THV had a significantly lower PPM rate compared with the BE-THV in patients with a small aortic annulus. As the indication for TAVI expands into lower risk and younger patients in whom the valves are expected to function for a longer period, a strategy to avoid PPM is crucial especially in patients with a small annulus. This study will provide important information for device selection to maximize the EOA and mitigate the risk of PPM in these patients.

Small aortic annulus is commonly seen in Japanese patients, and avoiding PPM following TAVI is an important concern. Due to its supra-annular design, SE-THV implantation results in a larger EOA with more favorable acute hemodynamic parameters with less PPM. This is useful information for the device selection process for TAVI. Additional research with larger cohorts and longterm follow-up is required to solidify the conclusions of this study.

\section{Disclosure}

R.M. has received grant support from Edwards Lifesciences and is a consultant for Medtronic. All other authors do not have conflicts of interest to disclose

Y.J.A. is a member of Circulation Journal' Editorial Team.

\section{IRB Information}

Medical Ethics Committee at St. Marianna University School of Medicine, reference no. 4446.

\section{Acknowledgments}

None.

\section{Data Availability}

The deidentified participant data will not be shared. 


\section{References}

1. Leon MB, Smith CR, Mack MJ, Makkar RR, Svensson LG, Kodali SK, et al. Transcatheter or surgical aortic-valve replacement in intermediate-risk patients. $N$ Engl J Med 2016; 374: $1609-1620$.

2. Mack MJ, Leon MB, Thourani VH, Makkar R, Kodali SK, Russo M, et al. Transcatheter aortic-valve replacement with a balloon-expandable valve in low-risk patients. $N$ Engl J Med 2019; 380: 1695-1705.

3. Popma JJ, Deeb GM, Yakubov SJ, Mumtaz M, Gada H, O'Hair $\mathrm{D}$, et al. Transcatheter aortic-valve replacement with a selfexpanding valve in low-risk patients. $N$ Engl J Med 2019; 380: $1706-1715$.

4. Rahimtoola SH. The problem of valve prosthesis-patient mismatch. Circulation 1978; 58: 20-24.

5. Head SJ, Mokhles MM, Osnabrugge RL, Pibarot P, Mack MJ, Takkenberg JJ, et al. The impact of prosthesis-patient mismatch on long-term survival after aortic valve replacement: A systematic review and meta-analysis of 34 observational studies comprising 27186 patients with 133141 patient-years. Eur Heart J 2012; 33: 1518-1529.

6. Fallon JM, DeSimone JP, Brennan JM, O'Brien S, Thibault DP, DiScipio AW, et al. The incidence and consequence of prosthesis-patient mismatch after surgical aortic valve replacement. Ann Thorac Surg 2018; 106: 14-22.

7. Pibarot P, Weissman NJ, Stewart WJ, Hahn RT, Lindman BR, McAndrew T, et al. Incidence and sequelae of prosthesis-patient mismatch in transcatheter versus surgical valve replacement in high-risk patients with severe aortic stenosis: A PARTNER trial cohort analysis. J Am Coll Cardiol 2014; 64: 1323-1334.

8. Zorn GL 3rd, Little SH, Tadros P, Deeb GM, Gleason TG, Heiser J, et al. Prosthesis-patient mismatch in high-risk patients with severe aortic stenosis: A randomized trial of a selfexpanding prosthesis. J Thorac Cardiovasc Surg 2016; 151: $1014-1022$.

9. Miyasaka M, Tada N, Taguri M, Kato S, Enta Y, Otomo T, et al. Incidence, predictors, and clinical impact of prosthesis-patient mismatch following transcatheter aortic valve replacement in Asian patients: The OCEAN-TAVI registry. JACC Cardiovasc Interv 2018; 11: 771-780.

10. Herrmann HC, Daneshvar SA, Fonarow GC, Stebbins A, Vemulapalli S, Desai ND, et al. Prosthesis-patient mismatch in patients undergoing transcatheter aortic valve replacement: From the STS/ACC TVT registry. J Am Coll Cardiol 2018; 72: $2701-2711$.

11. Une D, Ruel M, David TE. Twenty-year durability of the aortic Hancock II bioprosthesis in young patients: Is it durable enough? Eur J Cardiothorac Surg 2014; 46: 825-830.

12. Watanabe Y, Hayashida K, Takayama M, Mitsudo K, Nanto S, Takanashi S, et al. First direct comparison of clinical outcomes between European and Asian cohorts in transcatheter aortic valve implantation: The Massy study group vs. the PREVAIL
JAPAN trial. $J$ Cardiol 2015; 65: 112-116.

13. Hahn RT, Leipsic J, Douglas PS, Jaber WA, Weissman NJ, Pibarot P, et al. Comprehensive echocardiographic assessment of normal transcatheter valve function. JACC Cardiovasc Imaging 2019; 12: 25-34.

14. Yashima F, Yamamoto M, Tanaka M, Yanagisawa R, Arai T, Shimizu $\mathrm{H}$, et al. Transcatheter aortic valve implantation in patients with an extremely small native aortic annulus: The OCEAN-TAVI registry. Int J Cardiol 2017; 240: 126-131.

15. Puri R, Byrne J, Muller R, Baumbach H, Eltchaninoff H, Redwood $\mathrm{S}$, et al. Transcatheter aortic valve implantation in patients with small aortic annuli using a $20 \mathrm{~mm}$ balloon-expanding valve. Heart 2017; 103: 148-153.

16. Kappetein AP, Head SJ, Généreux P, Piazza N, van Mieghem NM, Blackstone EH, et al. Updated standardized endpoint definitions for transcatheter aortic valve implantation: The Valve Academic Research Consortium-2 Consensus Document. $J$ Am Coll Cardiol 2012; 60: $1438-1454$.

17. Ugur M, Suri RM, Daly RC, Dearani JA, Park SJ, Joyce LD, et al. Comparison of early hemodynamic performance of 3 aortic valve bioprostheses. J Thorac Cardiovasc Surg 2014; 148: 1940-1946.

18. Badano LP, Pavoni D, Musumeci S, Frassani R, Gianfagna P, Baldassi M, et al. Stented bioprosthetic valve hemodynamics: Is the supra-annular implant better than the intra-annular? J Heart Valve Dis 2006; 15: 238-246.

19. Kulik A, Al-Saigh M, Chan V, Masters RG, Bedard P, Lam BK, et al. Enlargement of the small aortic root during aortic valve replacement: Is there a benefit? Ann Thorac Surg 2008; 85: 94-100.

20. Nielsen PH, Hjortdal V, Modrau IS, Jensen H, Kimose HH, Terp K, et al. Durability after aortic valve replacement with the Mitroflow versus the Perimount pericardial bioprosthesis: A single-centre experience in 2393 patients. Eur J Cardiothorac Surg 2016; 49: 1705-1710.

21. Senage T, Le Tourneau T, Foucher Y, Pattier S, Cueff C, Michel $\mathrm{M}$, et al. Early structural valve deterioration of Mitroflow aortic bioprosthesis: Mode, incidence, and impact on outcome in a large cohort of patients. Circulation 2014; 130: 2012-2020.

22. Issa IF, Poulsen SH, Waziri F, Torp Pedersen C, Nielsen PH, Riber L, et al. Structural valve deterioration in the Mitroflow biological heart valve prosthesis. Eur J Cardiothorac Surg 2018; 53: $136-142$.

23. Clavel MA, Webb JG, Pibarot P, Altwegg L, Dumont E, Thompson $\mathrm{C}$, et al. Comparison of the hemodynamic performance of percutaneous and surgical bioprostheses for the treatment of severe aortic stenosis. J Am Coll Cardiol 2009; 53: $1883-1891$.

24. Rogers T, Steinvil A, Gai J, Torguson R, Koifman E, Kiramijyan $\mathrm{S}$, et al. Choice of balloon-expandable versus self-expanding transcatheter aortic valve impacts hemodynamics differently according to aortic annular size. Am J Cardiol 2017; 119: 900-904. 